\title{
Portal vein ligation and in situ liver splitting in metastatic liver cancer
}

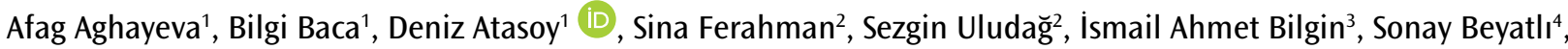 \\ İsmail Mihmanlı ${ }^{5}$, İsmail Hamzaoğlu ${ }^{3}$
}

ABSTRACT The most serious complication after major liver resection is liver failure. Depending on preoperative liver function, a future liver remnant of $25 \%-40 \%$ is considered sufficient to avoid postoperative liver failure. A new technique known as portal vein ligation combined with in situ splitting has been developed to obtain rapid liver hypertrophy. Herein, we present a case where we performed portal vein ligation combined with in situ splitting. A 37-year-old male patient with a diagnosis of sigmoid adenocarcinoma and liver metastasis underwent anterior resection because of an obstructing sigmoid tumor and received palliative chemotherapy. After chemotherapy, abdominal computed tomography revealed a lesion, $50 \mathrm{~mm}$ in diameter, localized between segments 5-8 of the liver on the bifurcation of the anteroposterior segmental branch of the right portal vein. Computed tomography volumetric assessments of the liver were performed in the preoperative period, and it was found that the remnant left liver volume was less than $25 \%$. In the first stage, portal vein ligation and in situ splitting of the liver parenchyma were performed. On the second and sixth postoperative days, computed tomography revealed hypertrophy of the left liver lobe. On the sixth day, a right hepatectomy was performed. Portal vein ligation combined with in situ splitting has been used by surgeons worldwide to obtain rapid and adequate liver hypertrophy. This new approach yields hope for patients with locally advanced liver tumors and may increase the number of curative resections for primary or metastatic liver tumors.

Cite this paper as: Aghayeva A, Baca B, Atasoy $D$, Ferahman $S$, Uludağ $S$, Bilgin IA, et al. Portal vein ligation and in situ liver splitting in metastatic liver cancer. Turk J Surg 2018; 34(4): 327-330.

'Department of General Surgery, Acibadem University School of Medicine Atakent Hospital, İstanbul, Turkey

${ }^{2}$ Department of General Surgery, İstanbul University Cerrahpaşa School of Medicine, Istanbul, Turkey

${ }^{3}$ Department of General Surgery, Acıbadem University School of Medicine Maslak Hospital, İstanbul, Turkey

${ }^{4}$ Student of Acibadem University School of Medicine, İstanbul, Turkey

${ }^{5}$ Department of Radiology, İstanbul University Cerrahpaşa School of Medicine, İstanbul, Turkey

This study was presented at the $19^{\text {th }}$ National Surgical Congress, 16-20 April 2014, Antalya, Turkey.

Corresponding Author Afag Aghayeva e-mail:aghayevaa@gmail.com

Received: 31.01 .2016 Accepted: 19.04.2016 OCopyright 2018 by Turkish Surgical Association

Available online at turkjsurg.com
Keywords: Portal vein ligation, in situ liver splitting, metastatic liver cancer

\section{INTRODUCTION}

One of the most important limiting factors for major liver resection is insufficient remnant liver volume. Depending on preoperative liver function, a liver remnant of $25 \%-40 \%$ is considered sufficient to avoid postoperative liver failure $(1,2)$. Portal vein embolization (PVE), chemotherapy, local ablation, and surgical portal vein ligation have been developed to induce liver tissue hypertrophy before major liver resection. In situ liver splitting and portal vein ligation (PVL) have been developed to induce rapid and effective hepatic hypertrophy as an alternative to these methods (3). In this approach, at the first stage, the hepatic vein, artery, and hepatic canal are preserved while PVL is performed; then, the liver parenchyma is split. At the second stage, the hepatic artery, vein, and hepatic canals are tied and the approach is completed with hepatectomy. This technique has been well accepted and used with good outcomes worldwide. Herein, we present a case where we performed PVL combined with in situ liver splitting.

\section{CASE PRESENTATION}

A 37-year-old male patient with a diagnosis of sigmoid adenocarcinoma and liver metastasis ( $\left.C T_{4} N_{1} M_{1}\right)$ underwent anterior resection in December 2012 because of an obstructing sigmoid tumor; he also underwent palliative chemotherapy. After the chemotherapy, abdominal computed tomography (CT) revealed that there was no regression over the metastatic lesions localized in the right lobe of the liver; thus, a right hepatectomy procedure was planned. A written informed consent was obtained from the patient. Abdominal CT revealed a lesion, $50 \mathrm{~mm}$ in diameter, localized between segments 5 to 8 of liver on the bifurcation of the anteroposterior segmental branch of the right portal vein (Figure 1). According to abdominal CT volumetric evaluation during the preoperative period, the volume of the left liver remnant was less than $25 \%$ and would not be sufficient for liver function.

In the first stage, perioperative ultrasound was performed to evaluate the left lobe. Only a subcapsular millimetric nodule was detected. The right portal vein was transected with a vascular staple; the right hepatic artery, vein, and right hepatic canal were saved (Figure 2, 3), and the parenchymal dissection of the right liver lobe was performed with an ultrasonic dissector and isolated with a sterile plastic bag (Figure 4). Additionally, the subcapsular millimetric nodule localized to the left lobe was excised. At the end of the first stage of this approach, a drain was placed in the subhepatic region before closure of the abdomen. The total operation time was 210 minutes and the total amount of blood loss was $1000 \mathrm{ml}$. 
On postoperative days (PODs) 2 and 6 of the first operation, it was revealed by abdominal CT that the volume of the left lobe was hypertrophied by more than $25 \%$ (Figure 5). It was seen that the left lobe passed the midline, extending toward the spleen (Figure 6). For the second stage, the right hepatic vein was transected with a vascular staple, and the right hepatic artery and right hepatic canal, which had been saved during the first stage, were tied with $2 / 0$ silk sutures. Right hepatectomy was completed with removal of the previously split right liver parenchyma. The total operation time was 60 minutes, and the total blood loss was $50 \mathrm{~mL}$. After the second stage of surgery, the patient's INR, total bilirubin, and direct bilirubin levels were 1.61, $3.7 \mathrm{mg} / \mathrm{dl}$, and $2.82 \mathrm{mg} / \mathrm{dL}$, respectively. His AST and ALT levels were two times higher than the normal range. However, before his discharge from the hospital, the patient's liver func-

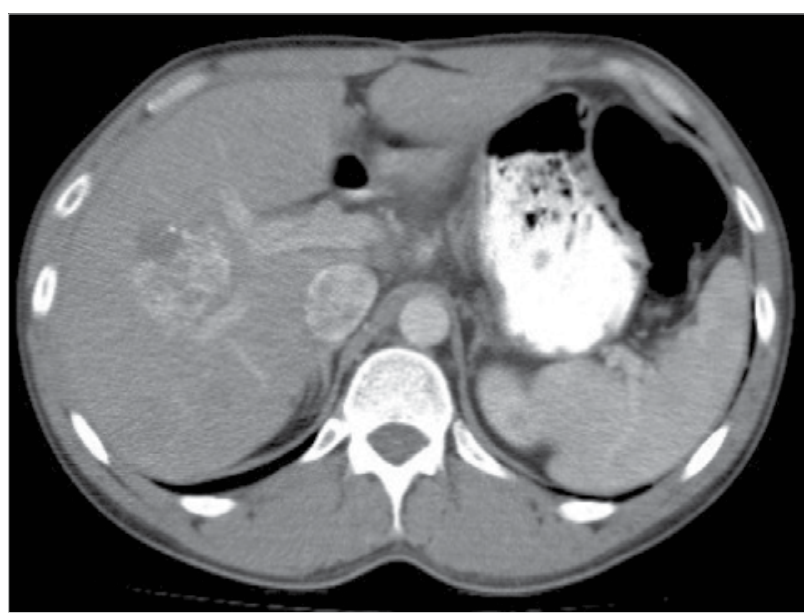

Figure 1. Preoperative image: lesion localized between segments 5 to 8 of the liver on the bifurcation of the anteroposterior segmental branch of the right portal vein

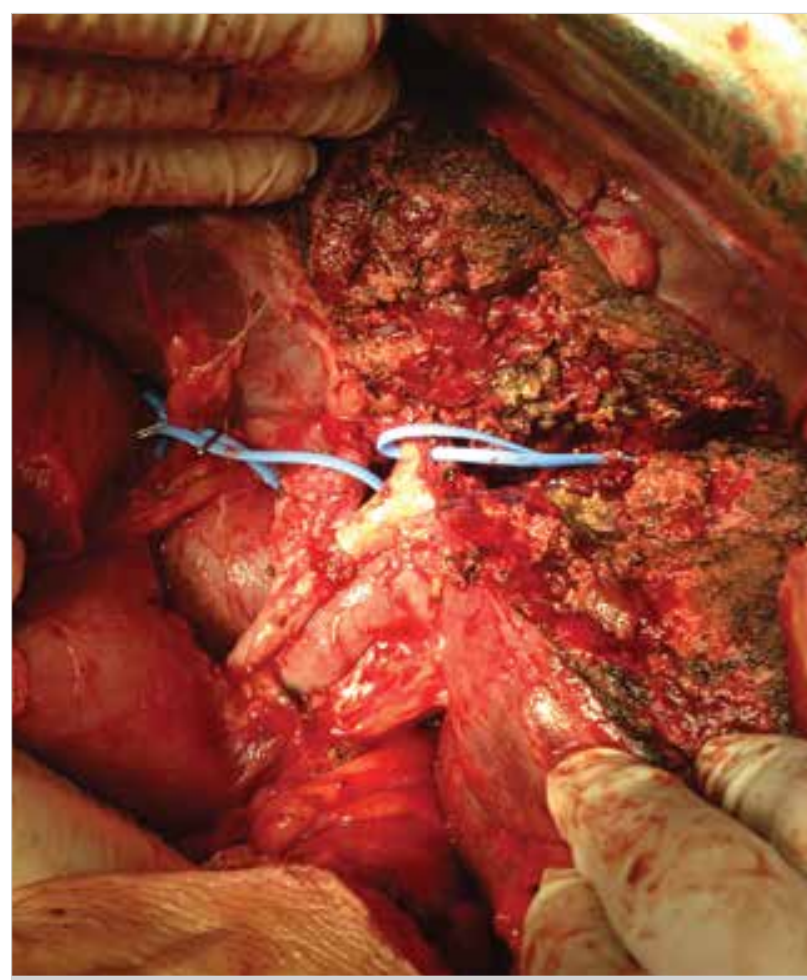

Figure 2. Right hepatic artery and right hepatic duct

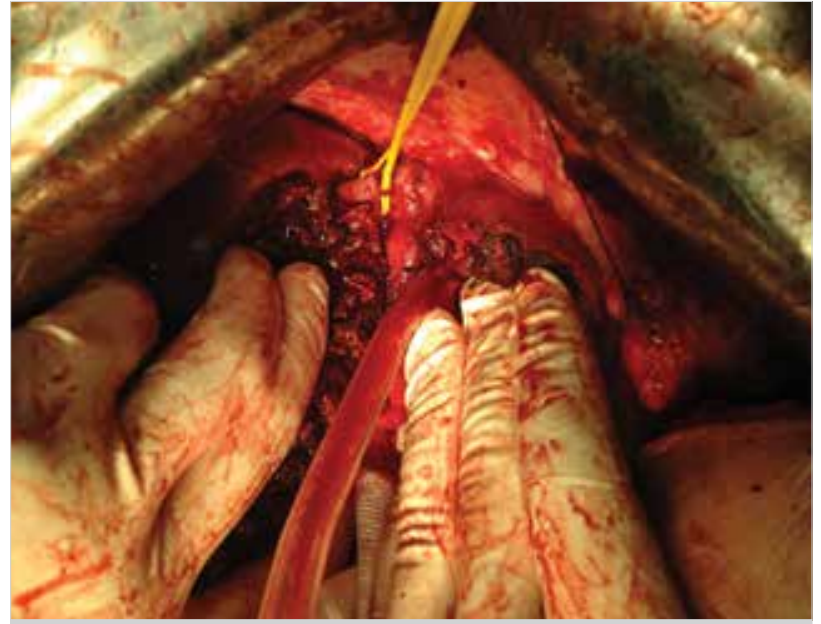

Figure 3. Right hepatic vein

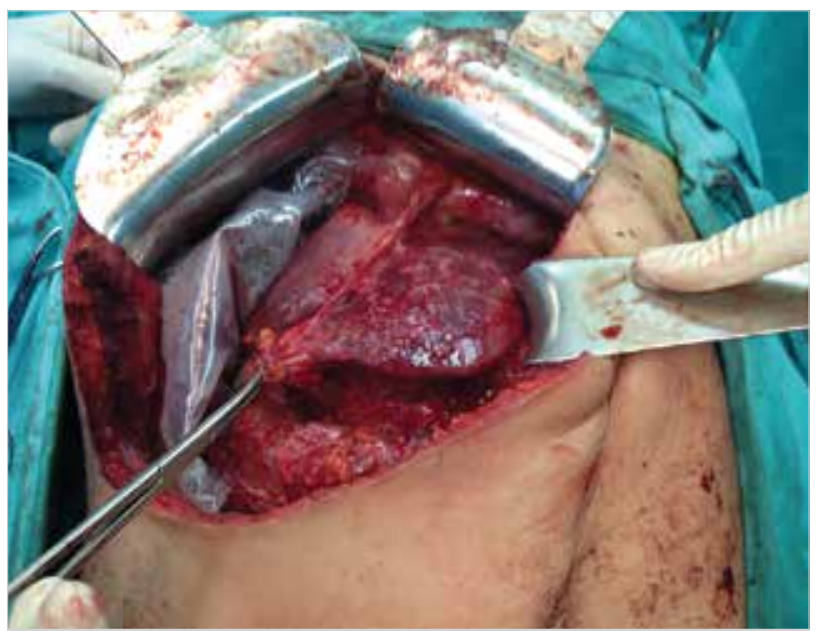

Figure 4. Isolation of split right liver lobe with a sterile plastic bag

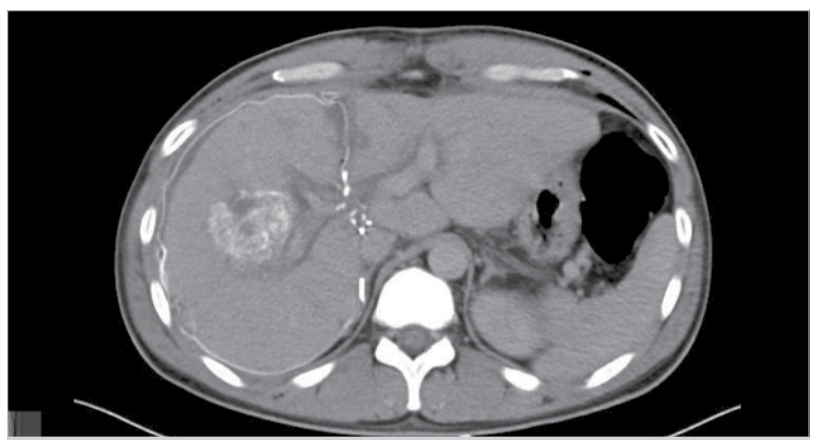

Figure 5. CT image of postoperative day 2

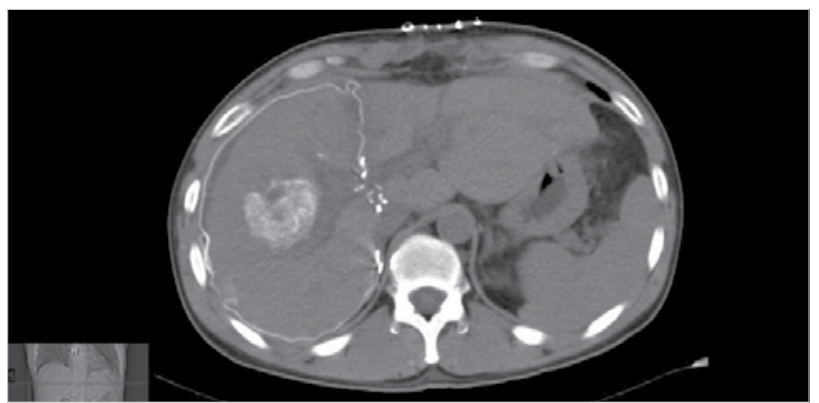

Figure 6. CT image of postoperative day 6 
tion tests were normal. The patient was discharged on POD 11 uneventfully. On POD 20, abdominal CT revealed that the left lobe was hypertrophied by passing through the midline up to the midclavicular line (Figure 7). Histopathological examination revealed a colonic-type metastatic adenocarcinoma on the right lobe of the liver at segment four. After a follow-up of two years, the patient has no recurrence. A recent PET-CT scan is shown in Figure 8.

\section{DISCUSSION}

The only curative treatment option for primary or metastatic liver cancers is surgical excision. However, in some patients with large tumors or with small tumors close to central main structures, the functional remnant liver volume after radical resection may be too small to maintain normal liver function. At least $25 \%-40 \%$ of the liver volume should be left after surgery to maintain normal liver function (3). Schnitzbauer et al.

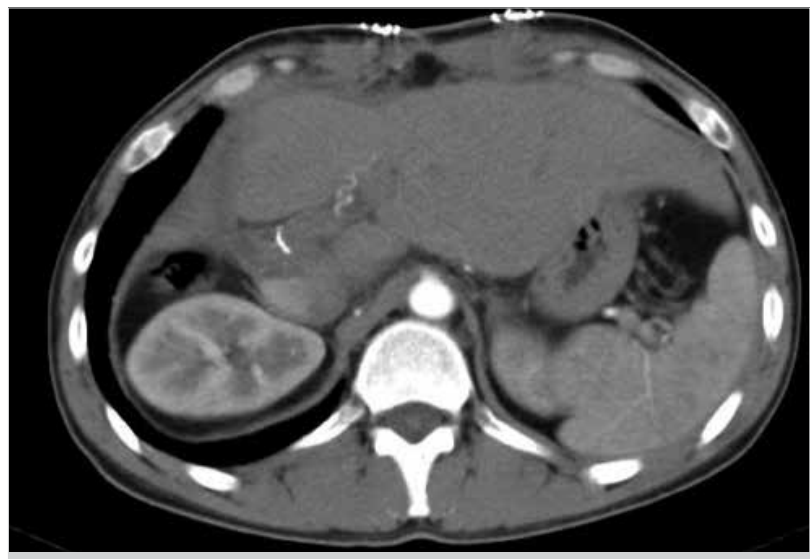

Figure 7. CT image of POD 20
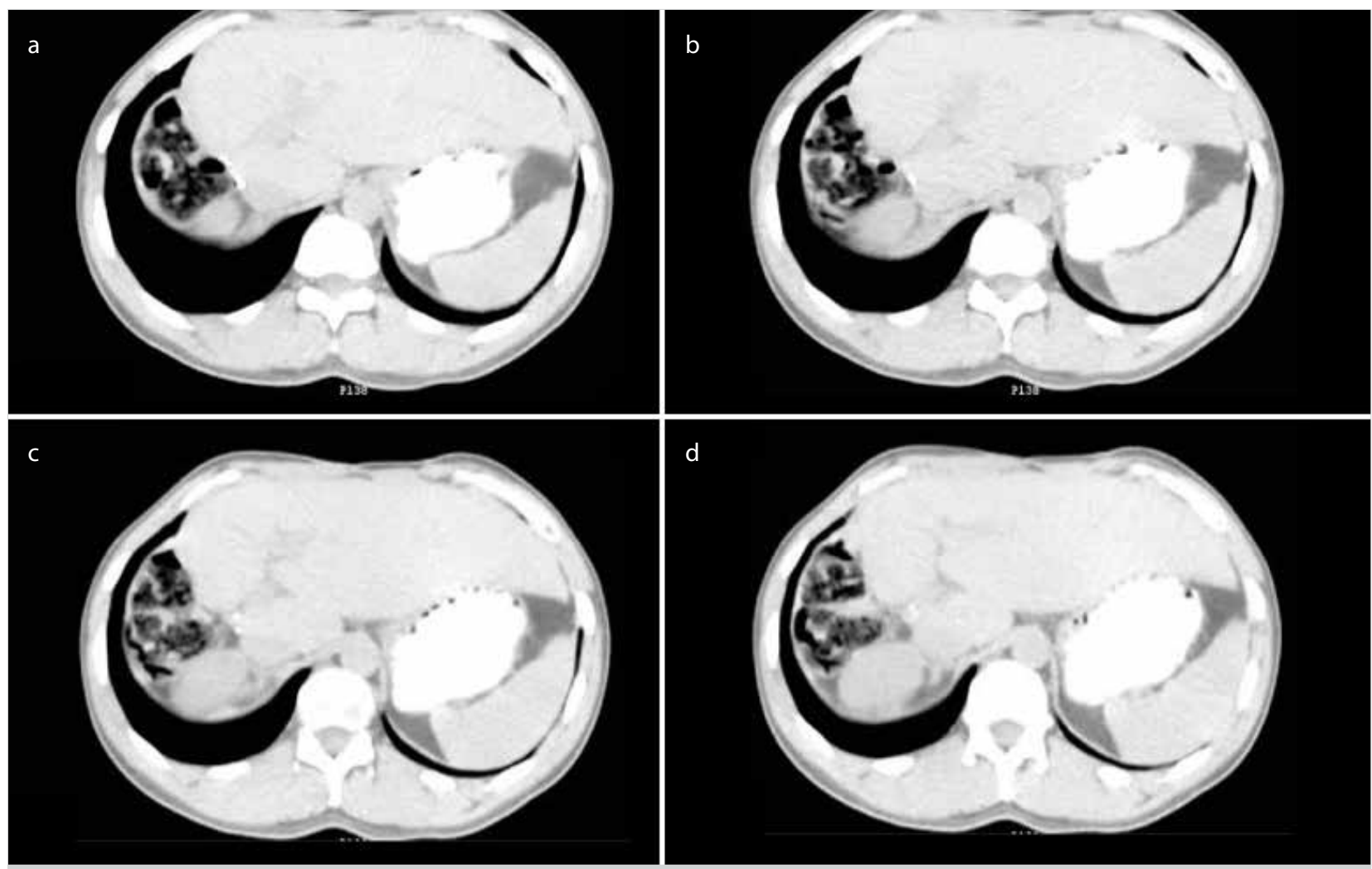

Figure 8. a-d. PET-CT images of second-year follow-up. Consecutive axial sections are presented 
eration, the presence of an underlying disease, and the size of the resection $(6,7)$. In the literature, biliary fistula, sepsis, and infection have been described as the major complications of ALPPS during the postoperative period (3).

Between 2011 and 2014, 320 ALPPS operations have been performed in 55 different centers worldwide (8). The age of the patient, type of tumor, timing of the operation during the first stage, and intraoperative blood transfusion are factors affecting the mortality. Patients over 60 years of age who are treated with ALPPS and those who undergo operations due to gallbladder carcinoma or cholangiocarcinoma show higher mortality rates (8).

The disadvantage of ALPPS that we encountered in our case was higher intraoperative blood loss compared to standard right hepatectomy.

\section{CONCLUSION}

Portal vein ligation combined with in situ splitting has been used to obtain rapid and adequate liver hypertrophy. This new approach could increase the number of curative resections in patients with locally advanced and primary or metastatic liver tumors.

Informed Consent: Written informed consent was obtained from patient who participated in this study.

Peer-review: Externally peer-reviewed.

Author Contributions: Concept - B.B., I.H., I.M.; Design - A.A., B.B., D.A.; Supervision - I.H., B.B., A.A.; Resource - S.F., S.U., I.A.B.; Materials - A.A., B.B., S.B.; Data Collection and/or Processing - A.A., S.B., I.A.B.; Analysis and/or Interpretation - D.A., A.A., B.B.; Literature Search - S.F., S.U., A.A.; Writing Manuscript - A.A., D.A., B.B.; Critical Reviews - B.B., I.H., I.M.
Conflict of Interest: The authors have no conflicts of interest to declare.

Financial Disclosure: The authors declared that this study has received no financial support.

\section{REFERENCES}

1. Tucker ON, Heaton N. The 'small for size' liver syndrome. Curr Opin Crit Care 2005; 11: 150-155. [CrossRef]

2. Tanaka K, Shimada H, Matsuo K, Ueda M, Endo I, Togo S. Remnant liver regeneration after two-stage hepatectomy for multiple bilobar colorectal metastases. Eur J Surg Oncol 2007; 33: 329-335. [CrossRef]

3. Schnitzbauer AA, Lang SA, Goessmann H, Nadalin S, Baumgart J, Farkas $S A$, et al. Right portal vein ligation combined with in situ splitting induces rapid left lateral liver lobe hypertrophy enabling 2 -staged extended right hepatic resection in small-for-size settings. Ann Surg 2012; 255: 405-414. [CrossRef]

4. H. Liu, S. Zhu. Present status and future perspectives of preoperative portal vein embolization. Am J Surg 2009; 197: 686-690. [CrossRef]

5. Aussilhou B, Lesurtel M, Sauvanet A, Farges O, Dokmak S, Goasguenet $\mathrm{N}$, et al. Right portal vein ligation is as efficient as portal vein embolization to induce hypertrophy of the left liver remnant. J Gastrointest Surg 2008; 12: 297-303. [CrossRef]

6. Sgourakis G, Sotiropoulos GC, Bockhorn M, Fuzas I, Radtke A, Molmenti EP, et al. Major liver resections for primary liver malignancies in the elderly. Acta Chir Belg 2009; 109: 340-344. [CrossRef]

7. Lang H, Sotiropoulos GC, Fruhauf NR, Dömland M, Paul A, Kind $E M$, et al. Extended hepatectomy for intrahepatic cholangiocellular carcinoma (ICC): when is it worthwhile? Single center experience with 27 resections in 50 patients over a 5 -year period. Ann Surg 2005; 241: 134-143.

8. Schadde E, Raptis DA, Schnitzbauer AA, Ardiles V, Tschuor C, Lesurtel $M$, et al. Prediction of mortality after ALPPS stage-1: an analysis of 320 patients from the international ALPPS Registry. Ann Surg 2015; 262: 780-786. [CrossRef] 